Research Note

\title{
Individualizing Periods of Commercial Exclusivity to Control Pricing for Drugs and Biologics
}

\author{
${ }^{1}$ Callie M. Blase, ${ }^{2}$ Brandon K. Rouault, ${ }^{3}$ Maia B. Zoller, ${ }^{4}$ Joshua V. Luff, ${ }^{5}$ Emma J. Lerch, ${ }^{6}$ Brynn N. \\ Lauterbach, ${ }^{7,8,9}$ Mark A. Brown, ${ }^{10}$ Joachim Storsberg and ${ }^{10,11}$ Christian Schmidt \\ ${ }^{1}$ Department of Marketing, Colorado State University, Fort Collins, CO 80523-1052, USA \\ ${ }^{2}$ Walter Scott College of Engineering, Colorado State University, Fort Collins, CO 80523-1052, USA \\ ${ }^{3}$ Department of Biochemistry and Molecular Biology, Colorado State University, Fort Collins, CO 80523-1052, USA \\ ${ }^{4}$ Department of Health and Exercise Science, Colorado State University, Fort Collins, CO 80523-1052, USA \\ ${ }^{5}$ Department of Biology, Colorado State University, Fort Collins, CO 80523-1052, USA \\ ${ }^{6}$ Department of Microbiology, Immunology and Pathology, Colorado State University, Fort Collins, CO 80523-1052, USA \\ ${ }^{7}$ Department of Clinical Sciences, Colorado State University, Fort Collins, CO 80523-1052, USA \\ ${ }^{8}$ Epidemiology Section, Colorado School of Public Health, Fort Collins, CO 80523-1052, USA \\ ${ }^{9}$ Cell and Molecular Biology Program, Colorado State University, Fort Collins, CO 80523-1052, USA \\ ${ }^{10}$ Department of Biomaterials and Healthcare, Division of Life Science and Bioprocesses, \\ Fraunhofer-Institute for Applied Polymer Research (IAP), 14476 Potsdam-Golm, Germany \\ ${ }^{11}$ Editorial Office, The American Journal of Immunology, S-207, 244, 5th Avenue, New York, NY, 10001 USA and S-71, 1A, \\ 400, King William St, Adelaide, SA 5000, Australia
}

Article history

Received: $14-08-2019$

Revised: 06-09-2019

Accepted: 11-09-2019

Corresponding Author:

Christian Schmidt

Fraunhofer Institute for

Applied Polymer Research,

Potsdam, Germany; The

American Journal of

Immunology, New York, NY,

USA and Adelaide, SA,

Australia

Email: schmidt102@gmail.com

\begin{abstract}
The pricing for immunologic agents and antibody-based therapeutics has increased precipitously in recent years. Among the key contributors to price hikes is the static practice of granting commercial exclusivity to innovator drugs and biologics. Herein, we present a mechanism for individualizing periods of commercial exclusivity to control pricing for drugs and biologics.
\end{abstract}

Keywords: Commercial Exclusivity, FDA, Immunologic Agents, Antibody-based Therapeutics

\section{Introduction}

A decades-long trend of precipitous price increases on prescription drugs and biologics has resulted in a variety of unintended consequences ranging from the exacerbation of health disparities to an upsurge in private insurance premiums. Although the biopharmaceutical industry claims that these price hikes occur due to ever-increasing cost of development and commercialization, a contributing factor is also manifest in the protection from competition associated with periods of commercial exclusivity granted to sponsors of innovator therapeutics by the United States (U.S.) Food and Drug Administration (FDA) and/or European Medicines Agency (EMA). In this context, exclusivity is defined as the period immediately following regulatory approval during which an agency provides regulatory protection from competition. These periods can range from 180 days to 7 years in length for the U.S. market (U.S. FDA, 2019) or 10 to 11 years for the European Union market (EMA, 2019) (Fig. 1).

Rather than adhering to the current static system of standardized periods of exclusivity, we propose a mechanism that assigns appropriate periods of exclusivity on a product-specific basis that is deemed to provide an adequate incentive for innovators relative to the anticipated profitability of the product. In doing so, therapeutics that have greater market potential will be provided with less protection from competition. The allowance of increased competition, on an individualized basis, will thus prevent price gouging for most therapeutics while maintaining incentivization for the development of niche market products. 


\section{Average Cost of U.S. Therapy per Drug}

\begin{tabular}{|c|c|}
\hline $\begin{array}{l}2006 \\
\$ 1,868\end{array}$ & $\begin{array}{r}2017 \\
\$ 6,798\end{array}$ \\
\hline \multicolumn{2}{|c|}{ Current Periods of Exclusivity } \\
\hline $\begin{array}{l}\text { FDA } \\
180 \text { Days to } 7 \text { Years }\end{array}$ & $\begin{array}{r}\text { EMA } \\
10-11 \text { Years }\end{array}$ \\
\hline
\end{tabular}

Fig. 1: Average costs of U.S. Therapies/Drug in U.S. Dollars (upper) and Current Periods of Commercial Exclusivity in the U.S. and E.U. Markets

\section{Discussion}

Historically, government intervention in free markets has disrupted economic flow by being less responsive to real-time needs. This has resulted either in product shortages and corresponding price hikes, or extreme competition and loss of profit. The latter inevitably leads to a decrease in innovation. Nevertheless, there are ongoing efforts to regulate the pharmaceutical industry and enact regulations which are designed to achieve price transparency and, in some cases, require justification for price increases from drug manufacturers. However, such attempts to control price gouging have not been effective, to-date and may lead to legal issues regarding protection of intellectual property.

With Individualized Exclusivity Periods (IEP), these issues may be resolved while avoiding the legal pitfalls associated with transparency-focused efforts. Using the IEP method, sponsors would participate in either a period of minimal exclusivity (Option 1), meaning exclusivity will only be long enough for the sponsor to recover the cost of development; or the sponsor could participate in an alternative, longer exclusivity period (Option 2) which would be subject to price controls. Each sponsor would be given the choice between the two options, based upon which is best suited for their product.

With Option 1, the length of the exclusivity period would be based upon the product's cost of development (incurred by the sponsor), with the period determined as that which is estimated to recover these costs in the commercial market. Drug prices during the exclusivity period would, likewise, be based upon the aforementioned factors, such that prices would be established by taking the development costs and estimating a reasonable balance between the period of exclusivity and the price during that period.
With Option 2, the period of exclusivity would ensure the sponsor has exclusive commercial approval for a period not exceeding 10 years, in exchange for a negotiated price cap. This will ensure that the price will remain reasonable while also mitigating risks to returns-on-investment.

In both cases, the FDA would coordinate and determine the length of exclusivity using an established algorithm.

\section{Analysis}

The first option allows a sponsor to recover its costs prior to the introduction of competition. Once recovered, the potential approval of competitor products creates a pathway for lowering therapeutic product prices sooner than what would be accommodated under the current system. Financial return on investment is a critical point of concern for biopharmaceutical sponsors, as "... one of the key elements in the debate has been the enormous cost associated with the development of new drugs. Pharmaceutical companies can only afford to commit millions of dollars in research support for drug development if they have a reasonable expectation of recouping those expenditures" (United States, 1992). With this alternative establishing a secure path for return on investment, investors would be more willing to invest in a start-up or with other sponsors that command lower-than-average capital bases.

\section{Conclusion}

The IEP mechanism provides a framework of limited government intervention to yield an increase of competition, decrease of market prices and the promotion of innovation within the biopharmaceutical industry. In facilitating pricing strategy alternatives, IEP allows pharmaceutical companies to evaluate which option would 
be most effective in maximizing profit while providing consumers more affordable new-generation drugs and biologics. The potential impact on industry could be significantly positive for both sponsors and consumers.

\section{Authors' Contributions}

Callie M. Blase, Brandon K. Rouault, Maia B. Zoller, Joshua V. Luff and Emma J. Lerch: Wrote the first draft of the paper.

Brynn N. Lauterbach, Mark A. Brown, Joachim Storsberg and Christian Schmidt: Provided critical input and assisted in revising and improving the paper. All authors read and approved of the final manuscript.

\section{Ethics}

CMB, BKR, MBZ, JVL, EJL BNL, MAB, JS and CS report no conflicts of interest with regard to this report. CS is a member of the Editorial Board of The American Journal of Immunology and is waived from the Article Processing Fee for this contribution.

\section{References}

EMA, 2019. Market Exclusivity, European Medicines Agency. https://www.ema.europa.eu/en/glossary/marketexclusivity

U.S. FDA, 2019. Frequently Asked Questions on Patents and Exclusivity, U.S. Food and Drug Administration.

https://www.fda.gov/drugs/development-approvalprocess-drugs/frequently-asked-questions-patentsand-exclusivity

United States, 1992. Congress. House. Committee on Energy Commerce. Subcommittee on Health the Environment. Granting Additional Market Exclusivity to the Drug Ansaid: Hearing before the Subcommittee on Health and the Environment of the Committee on Energy and Commerce, House of Representatives, One Hundred Second Congress, Second Session. 